\title{
Field oriented control based on a 24-sector vector space decomposition for dual three-phase PMSM applied on electric ship propulsion
}

\author{
Mhammed Hasoun ${ }^{1}$, Aziz El Afia ${ }^{2}$, Mohamed Khafallah ${ }^{3}$, Karim Benkirane ${ }^{4}$ \\ 1,3,4 Departement of Electrical Engineering, Hassan II University, National High School of Electricity and Mechanics \\ "ENSEM", Morocco \\ ${ }^{2}$ Departement of Electrical Engineering, Hassan II University, National High School of Arts and Crafts "ENSAM", \\ Morocco \\ ${ }^{1,4}$ Departement of Research, Royal Navy School “ERN”, Morocco
}

\begin{tabular}{l} 
Article Info \\
Article history: \\
Received Aug 6, 2019 \\
Revised Apr 13, 2020 \\
Accepted Apr 23, 2020 \\
\hline Keywords: \\
Field Oriented Control (FOC) \\
Dual Three Phase Permanent \\
Magnet Synchronous Motor \\
(DTP-PMSM) \\
24-Sector Vector Space \\
Decomposition (24SVSD) \\
Dual Three Phase Voltage \\
Source Inverter (DTP-VSI) \\
Harmonic Currents
\end{tabular}

\section{Corresponding Author:}

Mhammed Hasoun, Departement of Electrical Engineering, Hassan II University, National High School of Electricityand Mechanics "ENSEM”, Casa, Morocco. Email: mhammedhasoun@gmail.com
This is an open access article under the $\underline{C C B Y-S A}$ license.

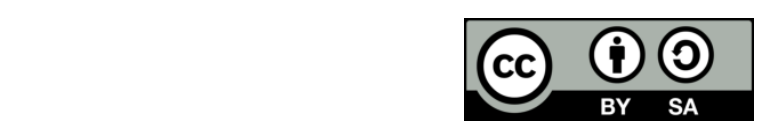

\begin{abstract}
A Field Oriented Control (FOC) strategy based on a 24-Sector Vector Space Decomposition (24SVSD) technique used to control a Dual Three-Phase Permanent Magnet Synchronous Motor (DTP-PMSM) applied on electric ship propulsion prototype is presented in this paper. This machine is supplied by Dual Three-Phase Voltage Source Inverter (DTP-VSI). This study carried out on these multiphase machines has revealed that the large zero sequence harmonic current components on $\left(\mathrm{z}_{1}, \mathrm{z}_{2}\right)$ subspace, constitutes major drawbacks; despite their advantages. The machine's dynamic model is accomplished in three two-dimensional and orthogonal subspaces. In order to reduce more extra stator harmonic currents that produces losses, the current work is also concering of to consider the three different approaches for the sake of boosting the machine's efficiency. Thus, the principle selection of the reference voltage vector and the time calculation method are presented in details. The proposed strategy effectiveness is validated by simulation results.
\end{abstract}

\section{INTRODUCTION}

Nowadays, the multiphase machines provide special characteristics compared with the three-phase counterparts. These machines offer the power segmentation and ameliorates the reliability and availability of the drive system. In electrical machines, the winding factors can be augmented, and the torque ripple reduced by using multiphases. Therefore, one of the perspective structures of multiphase systems is a Dual Three Phase (DTP) motor fed by two three-phase voltage source inverters (DTP-VSI).

The synchronous machines are widely used in industry, particularly the permanent magnet synchronous machines (PMSM). Thus, the DTP Machines notably PMSM drives has become very attractive in high performance control [1]. And DTP motor drives are widely used for electric propulsion ships, locomotive traction, electric/hybrid electric vehicles and aircrafts [2-6]. 
Several Space Vector Pulse Width Modulation (SVPWM) techniques for six-phase synchronous and induction drive system have been studied and developed in [7-9], such as conventional SVPWM and vector space decomposition (VSD) theory.

In order to control the voltage vectors components $\left(\mathrm{z}_{1}, \mathrm{z}_{2}\right)$ subspace, a Field Oriented Control (FOC) strategy applying 24-Sector Vector Space Decomposition (24SVSD) is presented and established, which can be divided into 24-sector Modulation strategy. For six-phase induction machine, the conventional VSD technique was reported in $[1,10]$. Then, the 12-sector Modulation is developed in [2].

According to the VSD control [1], the original machine's characteristics model, is transformed into three two-dimensional orthogonal subspaces in the stationary reference plane, identified as the torque-component $(\alpha, \beta)$ subspace, the harmonic-component $\left(\mathrm{z}_{1}, \mathrm{z}_{2}\right)$ subspace and the zero-sequence $\left(\mathrm{o}_{1}, \mathrm{o}_{2}\right)$ subspace. [11-15]. It should be noted, the fundamental components contribute to the conversion of the electromechanical energy. Whereas, the $\left(\mathrm{z}_{1}, \mathrm{z}_{2}\right)$ and $\left(\mathrm{o}_{1}, \mathrm{O}_{2}\right)$ current components do not contribute to the last conversion. Therefore, they are restricted by the stator resistance and leakage inductance [16-18]; also, the extra current harmonics only produce stator losses. To reduce these extra current harmonics, a Field Oriented Control strategy using a 24-Sector VSD (24SVSD) technique is proposed and simulated in this paper. Thus, three approaches have been also considered and developed. Finally, the simulation results show that the adopted approach reduces significally the harmonic components in $\left(\mathrm{z}_{1}, \mathrm{z}_{2}\right)$ subspace.

\section{MACHINE MODEL}

The structure of the DTP-PMSM windings fed by the VSI- DC sources, presenting spatially dual windings three-phase stator are shifted by 30 electrical degrees with two neutral independent points, as shown in three Figures 1,2 and 3.

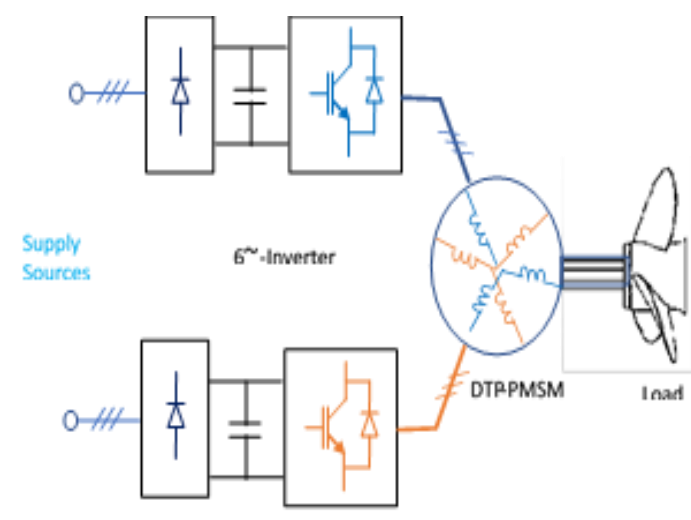

Figure 1. DTP-VSI feeding to DTP-PMSM

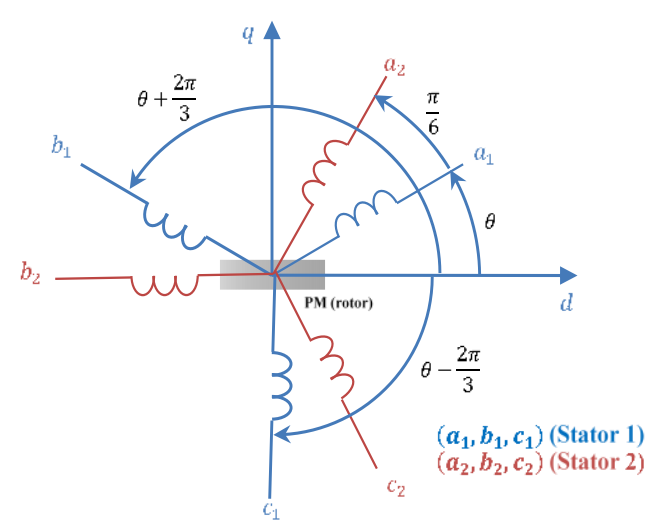

Figure 2. Machine windings

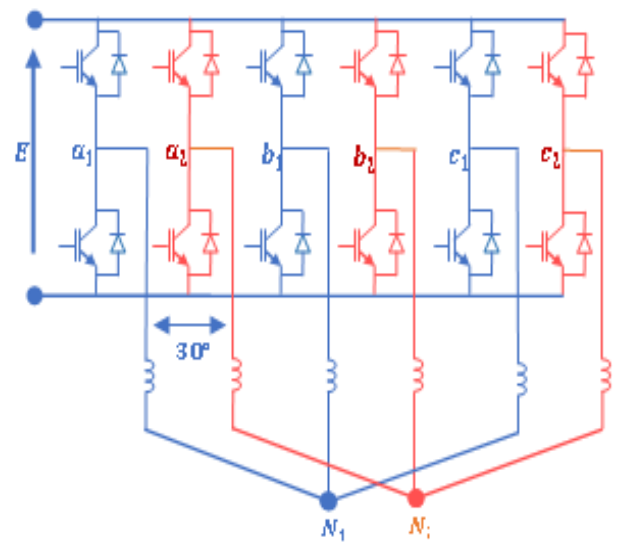

Figure 3. VSI-fed machine 
According to the VSD theory [1], the transformation matrix can be expressed as follows:

$$
T=\frac{1}{\sqrt{3}}\left[\begin{array}{cccccc}
1 & -\frac{1}{2} & -\frac{1}{2} & -\frac{\sqrt{3}}{2} & \frac{\sqrt{3}}{2} & 0 \\
0 & \frac{\sqrt{3}}{2} & -\frac{\sqrt{3}}{2} & \frac{1}{2} & \frac{1}{2} & -1 \\
1 & -\frac{1}{2} & -\frac{1}{2} & -\frac{\sqrt{3}}{2} & \frac{\sqrt{3}}{2} & 0 \\
0 & -\frac{\sqrt{3}}{2} & \frac{\sqrt{3}}{2} & \frac{1}{2} & \frac{1}{2} & -1 \\
1 & 1 & 1 & 0 & 0 & 0 \\
0 & 0 & 0 & 1 & 1 & 1
\end{array}\right]
$$

Applying the transformation matrix T, the Dual Three-Phase motor can be represented in three twodimensional decoupled mutually orthogonal planes $(\alpha-\beta),\left(\mathrm{z}_{1}, \mathrm{z}_{2}\right)$ and $\left(\mathrm{o}_{1}, \mathrm{o}_{2}\right)$.

According to the referenced assumptions in [19], the machine's all components equations can be identified in stationary configuration by following relationship:

$$
\begin{aligned}
& {\left[V_{\alpha \beta}\right]=\left[R_{S}\right]\left[i_{\alpha \beta}\right]+\frac{\mathrm{d}}{\mathrm{dt}}\left[\Psi_{\alpha \beta}\right]} \\
& {\left[\Psi_{\alpha \beta}\right]=\left[L_{\alpha \beta}\right]\left[i_{\alpha \beta}\right]+\Psi_{\mathrm{PM} \cdot} \cdot\left[\begin{array}{c}
\cos \theta \\
\sin \theta
\end{array}\right]} \\
& {\left[V_{z_{1,2}}\right]=\left[R_{S}\right]\left[i_{z_{1,2}}\right]+\left[L_{z}\right] \frac{\mathrm{d}}{\mathrm{dt}}\left[i_{z_{1,2}}\right]} \\
& {\left[\Psi_{z_{1,2}}\right]=\left[L_{z}\right]\left[i_{z_{1,2}}\right]} \\
& {\left[V_{o_{1,2}}\right]=\left[R_{S}\right]\left[i_{o_{1,2}}\right]+\left[L_{o}\right] \frac{\mathrm{d}}{\mathrm{dt}}\left[i_{o_{1,2}}\right]}
\end{aligned}
$$

where:

$$
\left[L_{\alpha \beta}\right]=\left[\begin{array}{cc}
\frac{\left(\mathrm{L}_{\mathrm{d}}+\mathrm{L}_{\mathrm{q}}\right)}{2}+\frac{\left(\mathrm{L}_{\mathrm{d}}-\mathrm{L}_{\mathrm{q}}\right)}{2} \cos 2 \theta & \frac{\left(\mathrm{L}_{\mathrm{d}}-\mathrm{L}_{\mathrm{q}}\right)}{2} \sin 2 \theta \\
\frac{\left(\mathrm{L}_{\mathrm{d}}-\mathrm{L}_{\mathrm{q}}\right)}{2} \sin 2 \theta & \frac{\left(\mathrm{L}_{\mathrm{d}}+\mathrm{L}_{\mathrm{q}}\right)}{2}-\frac{\left(\mathrm{L}_{\mathrm{d}}+\mathrm{L}_{\mathrm{q}}\right)}{2} \cos 2 \theta
\end{array}\right]
$$

where:

- $\left(\mathrm{L}_{\mathrm{d}}, \mathrm{L}_{\mathrm{q}}\right)$ : Direct and indiret inductances;

- $\left(\mathrm{L}_{\mathrm{z}}, \mathrm{L}_{\mathrm{o}}\right)$ : Self transformed conventional and mutual leakage inductances;

- $\left(\Psi_{\mathrm{PM}}\right)$ : Flux produced by permanent magnet;

$-(\Theta)$ : Rotor position angle.

The VSD technique [7] allows expressed the machine components in three two submodels sach as: the order harmonics $12 K^{t h} \pm 1(K=1,2,3, \ldots)$ are located in the $(\alpha, \beta)$ subspace, the order harmonics $6 K^{\text {th }} \pm 1(K=1,3,5, \ldots)$ are transformed into the $\left(\mathrm{z}_{1}, \mathrm{z}_{2}\right)$ subspace and the order harmonics $3 K^{\text {th }}(K=$ $1,3,5, \ldots)$ are transformed into the zero-sequence subspace $\left(\mathrm{o}_{1}, \mathrm{o}_{2}\right)$.

The $(\alpha-\beta)$ current components contribute to the electromechanical conversion. However, the currents in $\left(\mathrm{z}_{1}, \mathrm{z}_{2}\right)$ and $\left(\mathrm{o}_{1}, \mathrm{O}_{2}\right)$ do not contribute efficiently in the electromechanical conversion which produces stator losses.

The transformation matrix must be used to represent the stationary $(\alpha, \beta)$ subspace in the rotating frame $(d, q)$ which is shown in the following [20]:

$$
T_{r}=\left[\begin{array}{ccc}
\cos \theta & \sin \theta & 0 \\
-\sin \theta & \cos \theta & 0 \\
0 & 0 & I_{4}
\end{array}\right]\left(I_{4}: \text { four-dimentional unit matrix }\right)
$$

The electric and mechanic equations for this model in (d-q) plane are expressed by:

$$
\begin{aligned}
& {\left[\begin{array}{l}
\mathrm{V}_{\mathrm{d}} \\
\mathrm{V}_{\mathrm{q}}
\end{array}\right]=\left[\begin{array}{cc}
\mathrm{R}_{\mathrm{s}} & 0 \\
0 & \mathrm{R}_{\mathrm{s}}
\end{array}\right]\left[\begin{array}{l}
\mathrm{i}_{\mathrm{d}} \\
\mathrm{i}_{\mathrm{q}}
\end{array}\right]+\frac{\mathrm{d}}{\mathrm{dt}}\left[\begin{array}{c}
\Psi_{\mathrm{d}} \\
\Psi_{\mathrm{q}}
\end{array}\right]+\frac{d \theta}{d t}\left[\begin{array}{c}
-\Psi_{\mathrm{q}} \\
\Psi_{\mathrm{d}}
\end{array}\right]} \\
& {\left[\begin{array}{c}
\Psi_{\mathrm{D}} \\
\Psi_{\mathrm{Q}}
\end{array}\right]=\left[\begin{array}{cc}
\mathrm{L}_{\mathrm{D}} & 0 \\
0 & \mathrm{~L}_{\mathrm{Q}}
\end{array}\right]\left[\begin{array}{l}
\mathrm{I}_{\mathrm{D}} \\
\mathrm{I}_{\mathrm{Q}}
\end{array}\right]+\sqrt{3}\left[\begin{array}{c}
\Psi_{\mathrm{PM}} \\
0
\end{array}\right]}
\end{aligned}
$$




$$
\Gamma_{e m}=p\left(i_{q} \Psi_{\mathrm{d}}-i_{d} \Psi_{\mathrm{q}}\right)
$$

where: $\mathrm{p}$ is the number of pair poles.

\section{RESEARCH METHOD "FOC BASED ON VSD TECHNIQUE"}

\subsection{DTP-SVPWM Strategy}

The Pulse Width Modulation (PWM) techniques have been the focus of many researches. The main goal of the PWM is to control the inverter output voltage and to reduce the harmonic content in the output voltage. To increase the output voltage, the space vector pulse width modulation (SVPWM) technique is applied. This technique is used for adjustable speed drives. By using sectors in SVPWM, the SVPWM can identify the position of reference vector and the switches can be operated by the mentioned sectors. Thus, the field orientation approach consists on need of the $(\alpha-\beta)$ subplane as being reference stator voltage vector produced by the control system. Then, the harmonics in $\left(\mathrm{z}_{1}-\mathrm{Z}_{2}\right)$ and $\left(\mathrm{o}_{1}, \mathrm{O}_{2}\right)$ subspaces produces only losses. So as to reduce these harmonics. The average voltage vectors produced in the two subspaces must be fixed at zero [21].

In the Figure 4, two Proportional Integral regulators are used in the current control structure which generates the direct and indirect voltage reference, especially $\mathrm{V}_{\mathrm{d}}{ }^{*}$ and $\mathrm{V}_{\mathrm{q}}{ }^{*}$. Furthermore, the closed-loop speed regulator yields the indirect-axis current. The speed control can be achieved by controlling the q-axis current iq provided that the $d$-axis current component $i_{d}$ is kept at zero [22-24]. Therefore, the control strategy of $\mathrm{id}=0$ is a relatively simple method in ordinary 3-phase PMSM control strategy. When the d-axis stator current winding id $=0$, the mechanic (11) becomes:

$$
\Gamma_{\mathrm{em}}=\mathrm{p} \cdot \mathrm{i}_{\mathrm{q}} \cdot \Psi_{\mathrm{d}}=\mathrm{p} \cdot \mathrm{i}_{\mathrm{q}} \cdot \Psi_{\mathrm{PM}}
$$

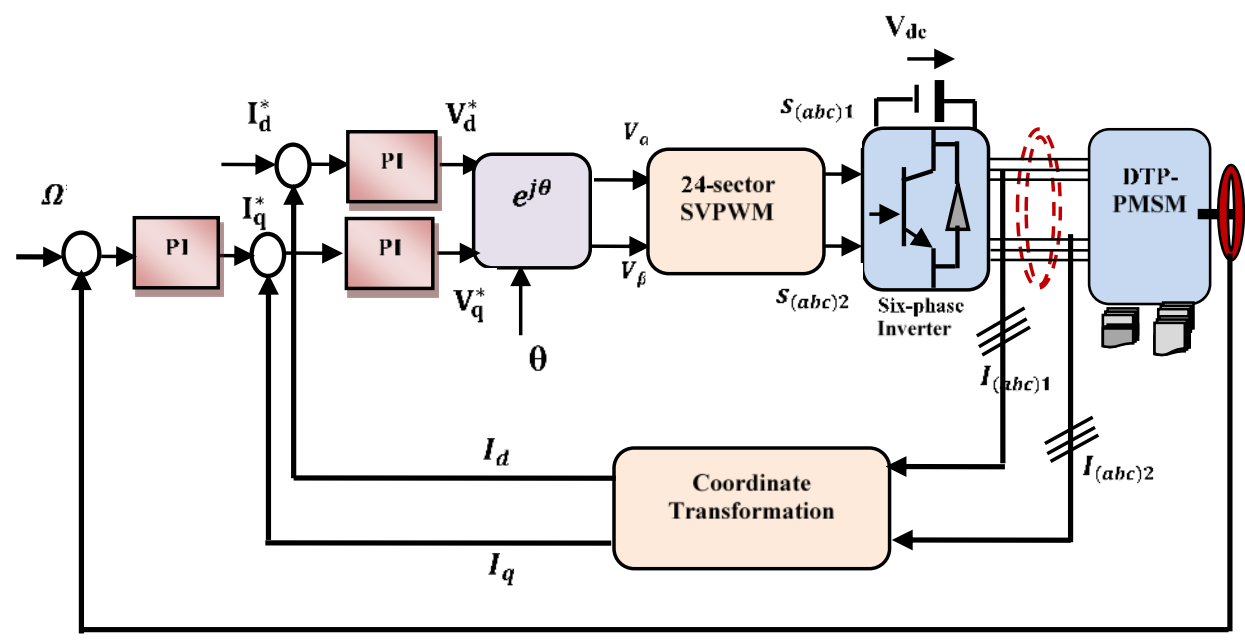

Figure 4. Machine's field oriented control under VSD technique

\subsection{4-Sector Vector Spae Decomposition (24SVSD)}

The FOC technique for the machine drive is shown in Figure 4.

The relationship between phase voltages and device switch states is as follows:

$$
\left[\begin{array}{l}
V_{a 1} \\
V_{b 1} \\
V_{c 1} \\
V_{a 2} \\
V_{b 2} \\
V_{c 2}
\end{array}\right]=\frac{\mathrm{E}}{3}\left[\begin{array}{cccccc}
2 & -1 & -1 & 0 & 0 & 0 \\
-1 & 2 & -1 & 0 & 0 & 0 \\
-1 & -1 & 2 & 0 & 0 & 0 \\
0 & 0 & 0 & 2 & -1 & -1 \\
0 & 0 & 0 & -1 & 2 & -1 \\
0 & 0 & 0 & -1 & -1 & 2
\end{array}\right]\left[\begin{array}{l}
S_{a 1} \\
S_{b 1} \\
S_{c 1} \\
S_{a 2} \\
S_{b 2} \\
S_{c 2}
\end{array}\right]
$$

Where: - $\left(\mathrm{S}=\mathrm{S}_{\mathrm{a} 1}, \mathrm{~S}_{\mathrm{b} 1}, \mathrm{~S}_{\mathrm{c} 1}, \mathrm{~S}_{\mathrm{a} 2}, \mathrm{~S}_{\mathrm{b} 2}, \mathrm{~S}_{\mathrm{c} 2}\right)$ : Switching modes; - E: DC bus voltage. 
By using the matrix relationship (13) and the transformation matrix T, voltages in each submodel are expressed as follows:

$$
\left[\begin{array}{l}
V_{\alpha} \\
V_{\beta} \\
V_{z 1} \\
V_{z 2} \\
V_{01} \\
V_{02}
\end{array}\right]=T\left[\begin{array}{l}
V_{a 1} \\
V_{b 1} \\
V_{c 1} \\
V_{a 2} \\
V_{b 2} \\
V_{c 2}
\end{array}\right]
$$

Figure 3 shows the wingdings and DTP-VSI fed DTP-PMSM. A combinatorial analysis shows 64 switching modes. Therefore, 64 different voltage vectors can be applied to the machine. Each vector is represented by a decimal number, corresponding to binary numbers, considered in the order $\left[S_{\mathrm{a} 1} S_{\mathrm{b} 1} S_{\mathrm{c} 1} S_{\mathrm{a} 2}\right.$ $\mathrm{S}_{\mathrm{b} 2} \mathrm{~S}_{\mathrm{c} 2}$. Thus, the both figures 5 and 6 shows the schematic diagram of the space vectors based on VSD respectively in $(\alpha-\beta)$ and $\left(z_{1}-z_{2}\right)$ subspaces.

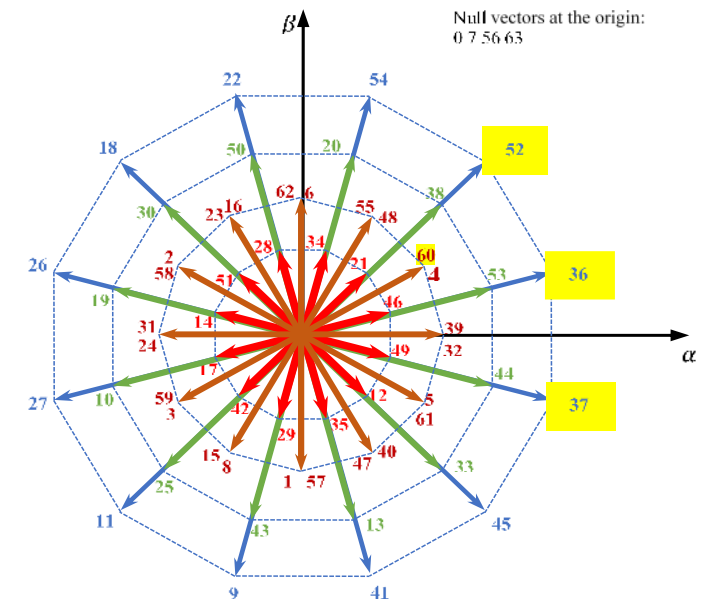

Figure 5. Diagram space vectors based on VSD in $(\alpha-\beta)$

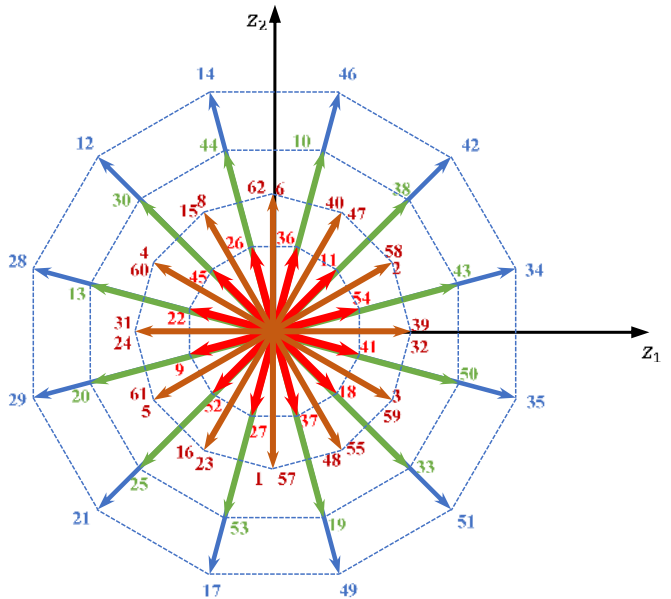

Figure 6. Diagram space vectors based on VSD in $\left(\mathrm{z}_{1}-\mathrm{z}_{2}\right)$

Regarding the Figures 5 and 6 , the $(\alpha-\beta)$ voltage vectors can be decomposed into four dodecagons with different magnitudes (from innermost to outermost: $\mathrm{D}_{1}, \mathrm{D}_{2}, \mathrm{D}_{3}, \mathrm{D}_{4}$ ) [25]. Their magnitudes are identified by the following relationship:

$$
\left\{\begin{array}{c}
U_{D 1}=\frac{\sqrt{(2-\sqrt{3})}}{\sqrt{3}} E \\
U_{D 2}=\frac{1}{\sqrt{3}} E \\
U_{D 3}=\frac{\sqrt{2}}{\sqrt{3}} E \\
U_{D 4}=\frac{\sqrt{(2+\sqrt{3})}}{\sqrt{3}} E
\end{array}\right.
$$

The maximum amplitude $(\alpha-\beta)$ voltage vectors become the minimum amplitude $\left(\mathrm{z}_{1}-\mathrm{z}_{2}\right)$ voltage vectors, whereas the others keep the same magnitude. 


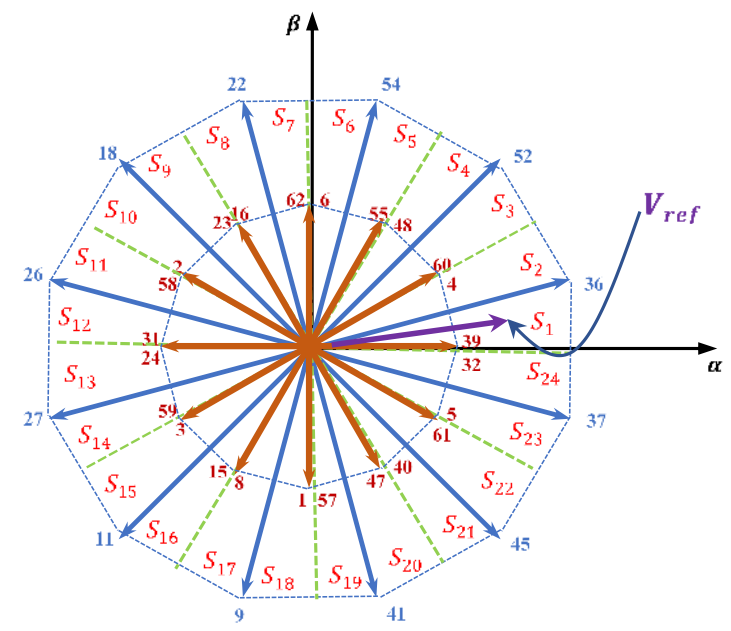

Figure 7. Diagram space vectors based on VSD having 12 maximum magnitude and 24 half-magnitude in $(\alpha-\beta)$ plane

In Figure 7, the 12 voltage vectors and 24 ones having respectively maximum and half magnitude divide the $(\alpha-\beta)$ subspace into 24 sectors. The voltage vectors selected allows having the smallest amplitude vectors in the $\left(\mathrm{Z}_{1}-\mathrm{Z}_{2}\right)$ plane, which guarantees the minimum current harmonics content in the $\left(\mathrm{z}_{1}-\mathrm{Z}_{2}\right)$ plane. Thus, leading to the decrease losses [3].

The combination of the maximum magnitude $(\alpha-\beta)$ vectors and the ones with half magnitude allows synthetizing the reference voltage vector $V_{\text {ref }}$ (Figure 7). According to the location of the reference voltage vector $V_{r e f}$ in the $(\alpha-\beta)$ subspace (Figure 5), the proposed strategy uses three vectors having the maximum magnitude and the fourth vector having half magnitude. In the sector $S_{1}$, the voltage vectors (37-36-52) combined with the fourth voltage vector (60) and zero voltage vectors (7-56) are employed. The time corresponding to each voltage vector is determinated by the following relationship:

$$
\left[\begin{array}{cccc}
V_{\alpha}^{1} & V_{\alpha}^{2} & V_{\alpha}^{3} & V_{\alpha}^{4} \\
V_{\beta}^{1} & V_{\beta}^{2} & V_{\beta}^{3} & V_{\beta}^{4} \\
V_{z_{1}}^{1} & V_{z_{1}}^{2} & V_{z_{1}}^{3} & V_{z_{1}}^{4} \\
V_{z_{2}}^{1} & V_{z_{2}}^{1} & V_{z_{2}}^{1} & V_{z_{2}}^{1}
\end{array}\right]\left[\begin{array}{c}
t_{1} \\
t_{2} \\
t_{3} \\
t_{4}
\end{array}\right]=T_{s}\left[\begin{array}{c}
V_{\text {ref } \alpha} \\
V_{\text {ref } \beta} \\
0 \\
0
\end{array}\right]
$$

where:

- $T_{S}:$ is the sample time;

- $\mathrm{t}_{1}, \mathrm{t}_{2}, \mathrm{t}_{3}$ and $\mathrm{t}_{4}$ : are the times corresponding to the four voltage vectors;

- $V_{X}^{k}$ : is the projection of $k^{\text {th }}$ voltage vector on the $\mathrm{x}$-axis $\left(\mathrm{x}=\alpha, \beta, \mathrm{z}_{1}, \mathrm{z}_{2}\right)$.

The time interval attributed to zero voltage vectors is the remaining time:

$$
t_{0}=T_{s}-\left(t_{1}+t_{2}+t_{3}+t_{4}\right)
$$

In order to allow the occurrence of, at most, two transitions during each PWM period, three approaches, using the 24-sector strategy should be considered. In the first approach (approach (1) henceforth), the switching sequence concerns the position of the null vectors in the middle and at the ends of the switching sequence. In the second approach (approach (2) henceforth), the null vector is placed at the ends of the switching sequence. In the third approach (approach (3) henceforth), the null vectors is placed in the middle of the switching sequence (Figure 8). 


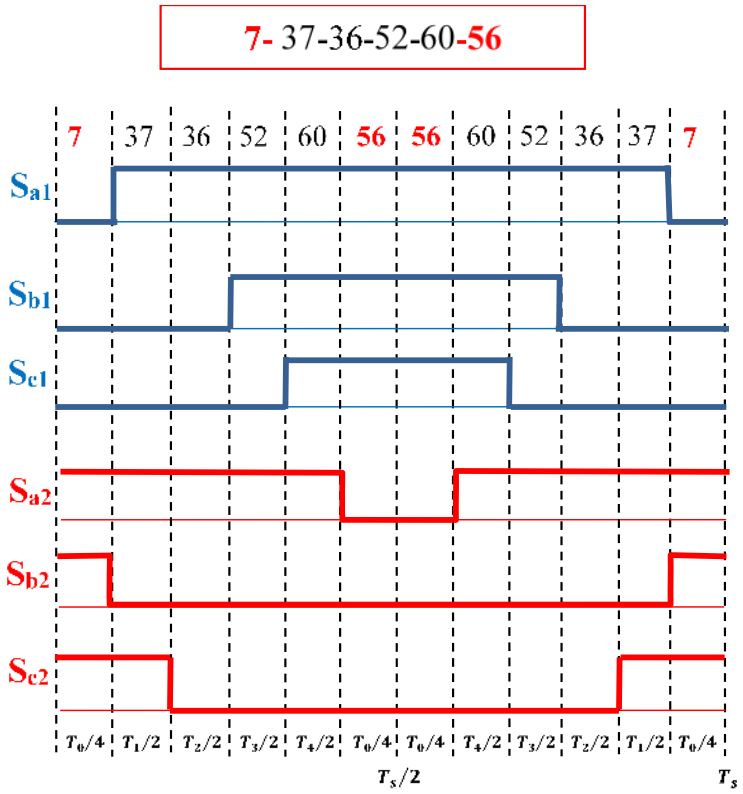

(a)

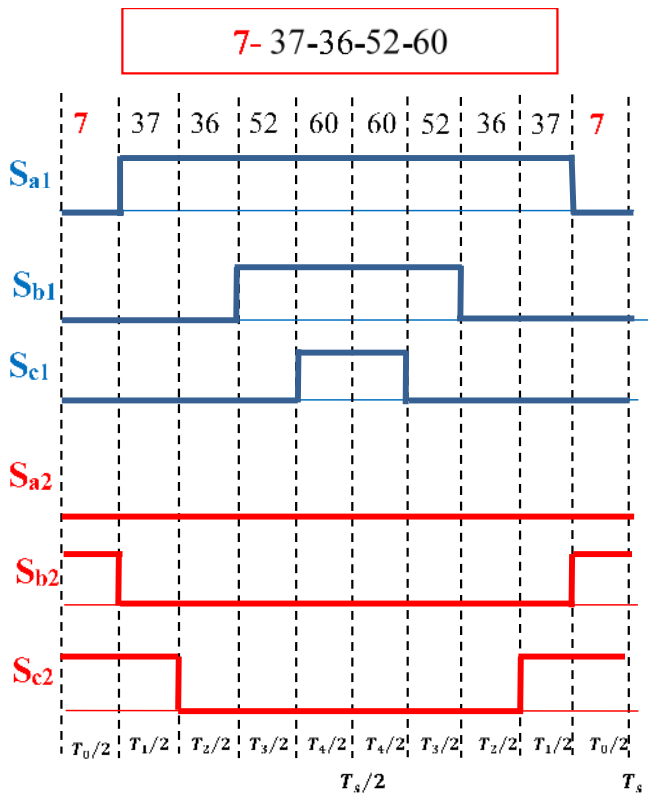

(b)

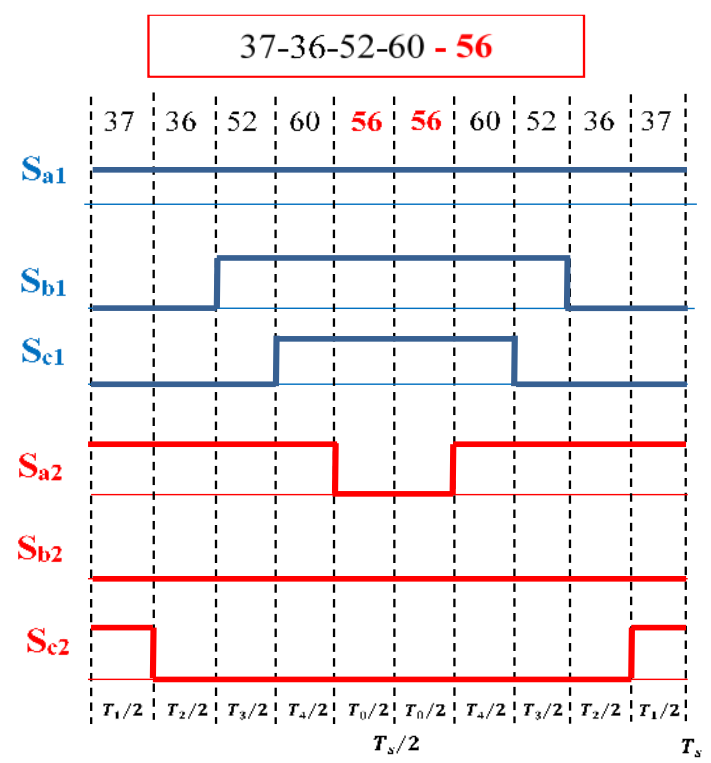

(c)

Figure 8. Switching sequence in sector 1 according to the placement of the null voltage vectors (a) Approach (1). (b) Approach (2). (c) Approach (3)

By applying the same reasoning to the other sectors, the times of four non-null vectors is given by the table below (Table 1).

Table 1. 24-sector modulation vectors applying times $\left(\mathrm{S}_{1}-\mathrm{S}_{12}\right)$

\begin{tabular}{|c|c|c|c|c|c|c|c|c|c|c|c|c|c|}
\hline & & $\mathrm{S}_{1}$ & $\mathrm{~S}_{2}$ & $\mathrm{~S}_{3}$ & $\mathrm{~S}_{4}$ & $\mathrm{~S}_{5}$ & $\mathrm{~S}_{6}$ & $\mathrm{~S}_{7}$ & $\mathrm{~S}_{8}$ & $\mathrm{~S}_{9}$ & $\mathrm{~S}_{10}$ & $\mathrm{~S}_{11}$ & $\mathrm{~S}_{12}$ \\
\hline $\mathrm{T}$ & $\mathrm{t}_{1}$ & $\mathrm{~T}_{1}$ & $-\mathrm{T}_{4}$ & $\mathrm{~T}_{6}$ & $-\mathrm{T}_{8}$ & $\mathrm{~T}_{10}$ & $-\mathrm{T}_{5}$ & $\mathrm{~T}_{11}$ & $-\mathrm{T}_{9}$ & $\mathrm{~T}_{12}$ & $-\mathrm{T}_{2}$ & $\mathrm{~T}_{3}$ & $-\mathrm{T}_{7}$ \\
\hline I & $t_{2}$ & $\mathrm{~T}_{2}$ & $\mathrm{~T}_{1}$ & $\mathrm{~T}_{7}$ & $\mathrm{~T}_{6}$ & $-\mathrm{T}_{4}$ & $\mathrm{~T}_{10}$ & $-\mathrm{T}_{8}$ & $\mathrm{~T}_{11}$ & $-\mathrm{T}_{5}$ & $\mathrm{~T}_{12}$ & $-\mathrm{T}_{9}$ & $\mathrm{~T}_{3}$ \\
\hline M & $t_{3}$ & $\mathrm{~T}_{3}$ & $\mathrm{~T}_{5}$ & $-\mathrm{T}_{1}$ & $\mathrm{~T}_{9}$ & $-T_{6}$ & $\mathrm{~T}_{2}$ & $-\mathrm{T}_{10}$ & $\mathrm{~T}_{7}$ & $-\mathrm{T}_{11}$ & $-\mathrm{T}_{4}$ & $-\mathrm{T}_{12}$ & $-\mathrm{T}_{8}$ \\
\hline $\begin{array}{l}\mathrm{E} \\
\mathrm{S}\end{array}$ & $\mathrm{t}_{4}$ & $\mathrm{~T}_{4}$ & $\mathrm{~T}_{3}$ & $\mathrm{~T}_{8}$ & $-\mathrm{T}_{1}$ & $\mathrm{~T}_{5}$ & $-\mathrm{T}_{6}$ & $\mathrm{~T}_{9}$ & $-\mathrm{T}_{10}$ & $\mathrm{~T}_{2}$ & $-\mathrm{T}_{11}$ & $\mathrm{~T}_{7}$ & $-\mathrm{T}_{12}$ \\
\hline
\end{tabular}


Table 1. 24-sector modulation vectors applying times $\left(\mathrm{S}_{13}-\mathrm{S}_{24}\right)$

\begin{tabular}{lccccccccccccccc}
\hline & & & & & & \multicolumn{3}{c}{ SECTORS } & & $\mathrm{S}_{22}$ & $\mathrm{~S}_{23}$ & $\mathrm{~S}_{24}$ \\
\hline $\mathrm{T}$ & $\mathrm{S}_{13}$ & $-\mathrm{T}_{1}$ & $\mathrm{~T}_{4}$ & $-\mathrm{T}_{6}$ & $\mathrm{~T}_{8}$ & $-\mathrm{T}_{10}$ & $\mathrm{~T}_{5}$ & $-\mathrm{T}_{11}$ & $\mathrm{~T}_{9}$ & $-\mathrm{T}_{12}$ & $\mathrm{~T}_{2}$ & $-\mathrm{T}_{3}$ & $\mathrm{~T}_{7}$ \\
$\mathrm{I}$ & $\mathrm{t}_{2}$ & $-\mathrm{T}_{2}$ & $-\mathrm{T}_{1}$ & $-\mathrm{T}_{7}$ & $-\mathrm{T}_{6}$ & $\mathrm{~T}_{4}$ & $-\mathrm{T}_{10}$ & $\mathrm{~T}_{8}$ & $-\mathrm{T}_{11}$ & $\mathrm{~T}_{5}$ & $-\mathrm{T}_{12}$ & $\mathrm{~T}_{9}$ & $-\mathrm{T}_{3}$ \\
$\mathrm{M}$ & $\mathrm{t}_{3}$ & $-\mathrm{T}_{3}$ & $-\mathrm{T}_{5}$ & $\mathrm{~T}_{1}$ & $-\mathrm{T}_{9}$ & $\mathrm{~T}_{6}$ & $-\mathrm{T}_{2}$ & $\mathrm{~T}_{10}$ & $-\mathrm{T}_{7}$ & $\mathrm{~T}_{11}$ & $\mathrm{~T}_{4}$ & $\mathrm{~T}_{12}$ & $\mathrm{~T}_{8}$ & $-\mathrm{T}_{2}$ \\
$\mathrm{E}$ & $\mathrm{t}_{4}$ & $-\mathrm{T}_{4}$ & $-\mathrm{T}_{3}$ & $-\mathrm{T}_{8}$ & $\mathrm{~T}_{1}$ & $-\mathrm{T}_{5}$ & $\mathrm{~T}_{6}$ & $-\mathrm{T}_{9}$ & $\mathrm{~T}_{10}$ & $-\mathrm{T}_{2}$ & $\mathrm{~T}_{11}$ & $-\mathrm{T}_{7}$ & $\mathrm{~T}_{12}$ \\
$\mathrm{~S}$ & & & & & & & & & & & &
\end{tabular}

Projecting voltage vectors on the $(\alpha-\beta)$ and $\left(z_{1}-z_{2}\right)$-axis in the relationship (16), the coefficients in Table 1 are given as follows:

$$
\left[\begin{array}{l}
T_{1} \\
T_{2} \\
T_{3} \\
T_{4} \\
T_{5} \\
T_{6} \\
T_{7} \\
T_{8} \\
T_{9} \\
T_{10} \\
T_{11} \\
T_{12}
\end{array}\right]=\frac{T_{8}}{2 E}\left[\begin{array}{cc}
1 & -\sqrt{3} \\
\sqrt{3}-1 & \sqrt{3}-1 \\
0 & 2 \\
2-\sqrt{3} & -1 \\
1 & -2+\sqrt{3} \\
\sqrt{3} & -1 \\
2-\sqrt{3} & 1 \\
-1+\sqrt{3} & 1-\sqrt{3} \\
1 & 2-\sqrt{3} \\
2 & 0 \\
\sqrt{3} & 1 \\
1 & \sqrt{3}
\end{array}\right]\left[\begin{array}{l}
v_{\text {ref } \alpha} \\
v_{\text {ref } \beta}
\end{array}\right]
$$

The relationship (17) makes it possible to determine the time allotted to zero voltage vectors.

The Table 2 as follows gives the final switching sequences for all sectors.

Table 2. 24-sector modulation switching sequences $\left(\mathrm{S}_{1}-\mathrm{S}_{12}\right)$

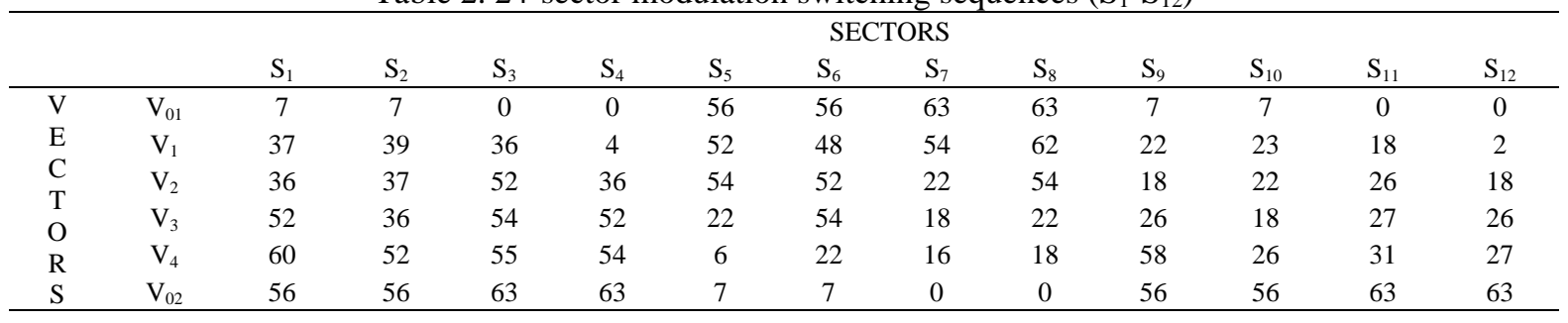

Table 2. 24-sector modulation switching sequences $\left(\mathrm{S}_{13}-\mathrm{S}_{24}\right)$

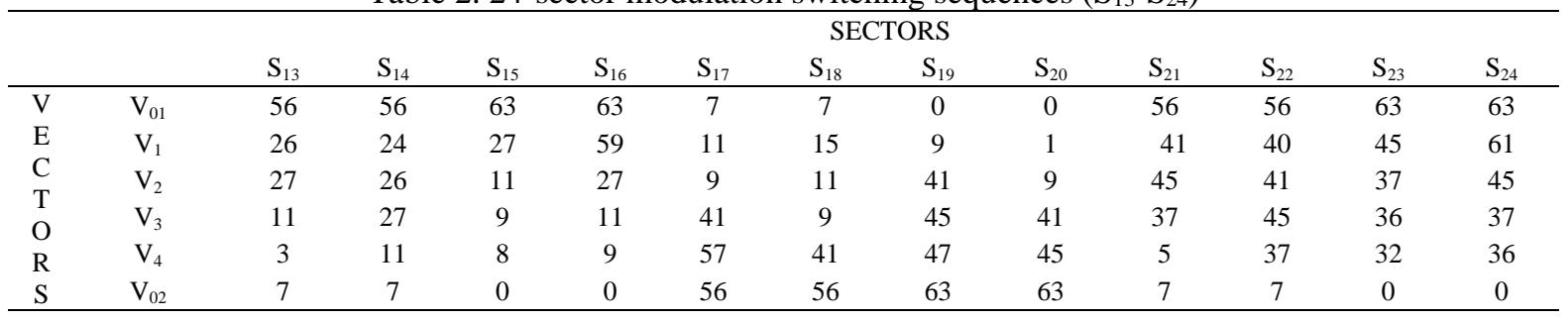

\section{SIMULATION RESULTS AND DISCUSSION}

The simulation tests were accomplished by using a 3-KW machine applied on electric ship prototype, whose parameters are indicated in Table 3 [19].

In all the simulation tests, the load torque is kept at $15 \mathrm{~N} . \mathrm{m}$, the machine speed is fixed at $300 \mathrm{rpm}$ and the inverter switching frequency is maintained at the same frequency $5 \mathrm{kHz}$. The figures $9-14$ show the simulation results of the proposed strategy.

As shown in Figure 9, in a period of 24 sectors, it is observed that 6 sectors remain with no switching for approaches (b) and (c). This allows a 25\% reduction of the switching compared with approach (a) where there is a continuous switching mode. Thus, a significant reduction of the switching losses is accomplished. 
Table 3. Machine's main parameters

\begin{tabular}{cc}
\hline Designation & Value/ unit \\
\hline DC bus voltage: $\mathrm{E}$ & $400 \mathrm{~V}$ \\
statoric resistance $: \mathrm{R}_{\mathrm{s}}$ & $1 \Omega$ \\
d-axis inductance $: \mathrm{L}_{\mathrm{d}}$ & $8.5 \mathrm{mH}$ \\
q-axis inductance $: \mathrm{L}_{\mathrm{q}}$ & $8.5 \mathrm{mH}$ \\
permanent magnet flux: $\Psi_{\mathrm{PM}}$ & $0.175 \mathrm{~Wb}$ \\
total inertia moment: $\mathrm{J}$ & $89.10^{-3} \mathrm{kgm}$ \\
total viscous friction coefficient: $\mathrm{f}$ & $0.01 \mathrm{Nms} / \mathrm{rad}$ \\
number of pair poles $: \mathrm{p}$ & 4 \\
\hline
\end{tabular}

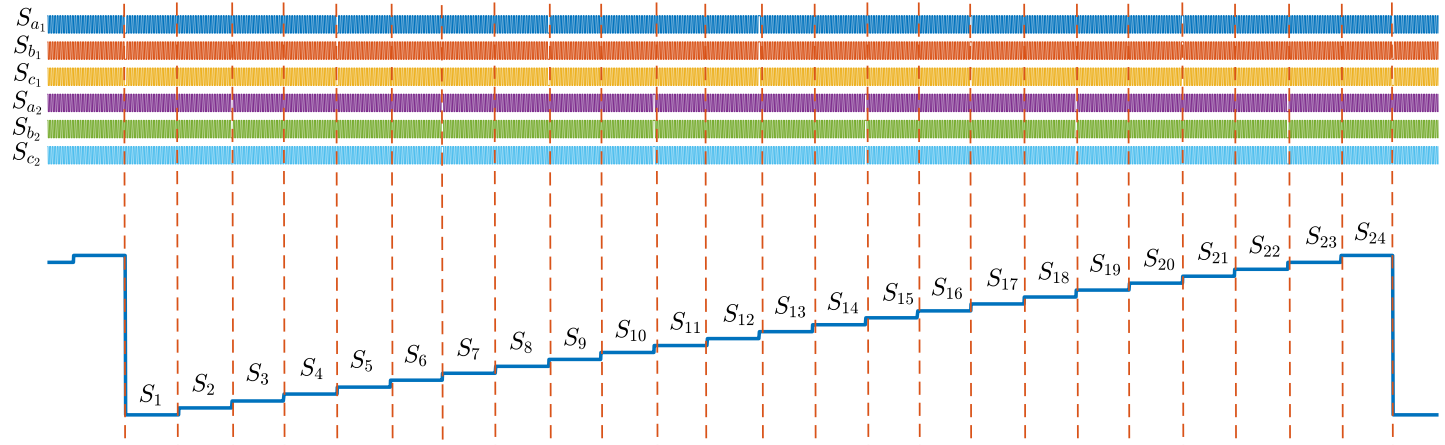

(a)

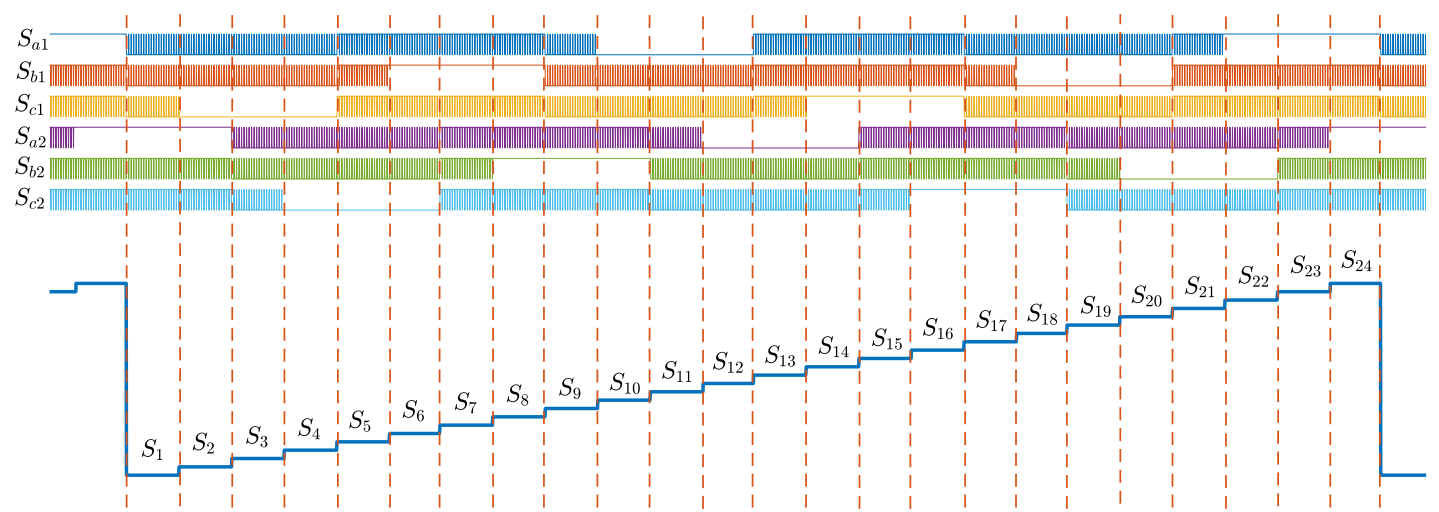

(b)

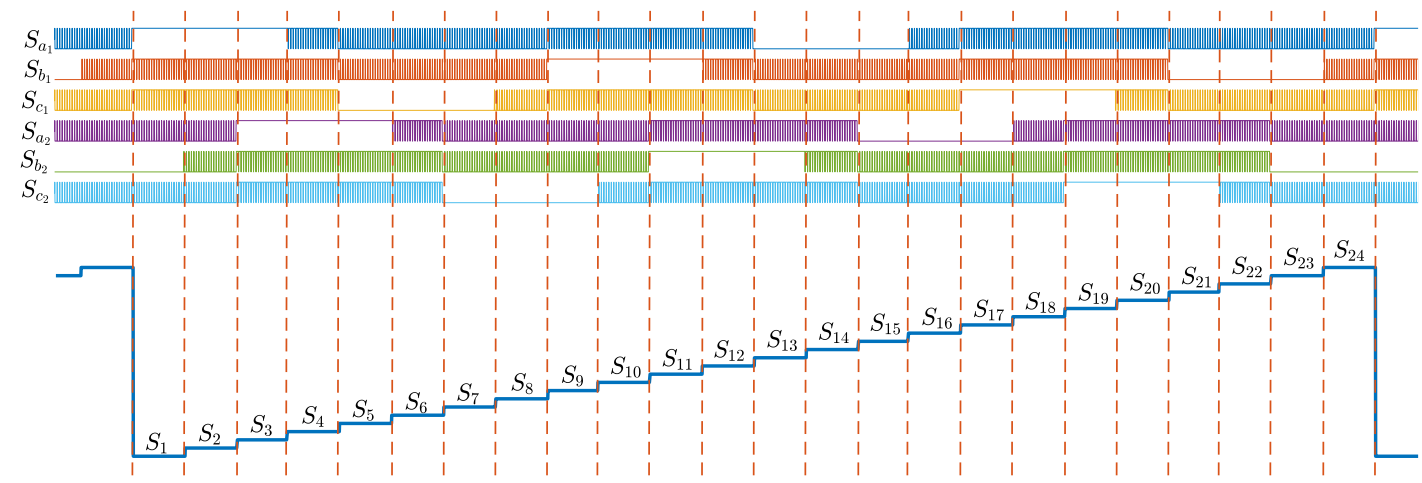

(c)

Figure 9. Swiching command and corresponding sectors in terms of positioning zero voltage vectors (a) Approach (1). (b) Approach (2). (c) Approach (3)

In Figure 10, the stator phase current resultant from the three presented approaches is extremely sinusoidal. The Figure 11 shows the harmonic current analysis significantly decreased to $1.05 \%$. Thus, the harmonic analysis shows that the THD is slightly lower in approach (1) compared to the two other 
approaches (2) and (3). It should be noted that these stator current components will only produce losses since they have no contribution in the elaboration of air gap flux.

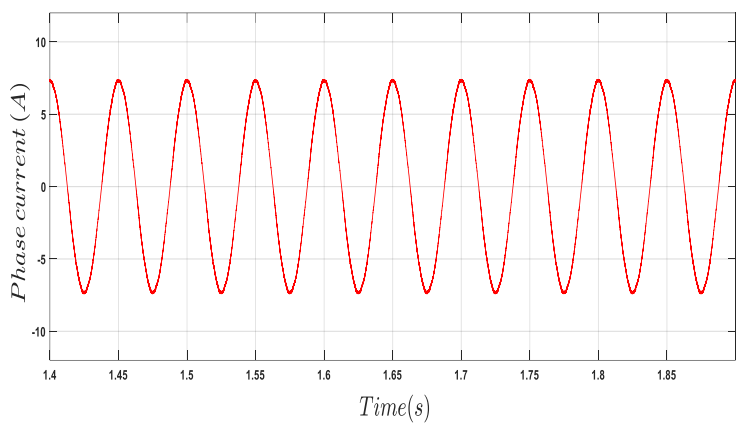

(a)

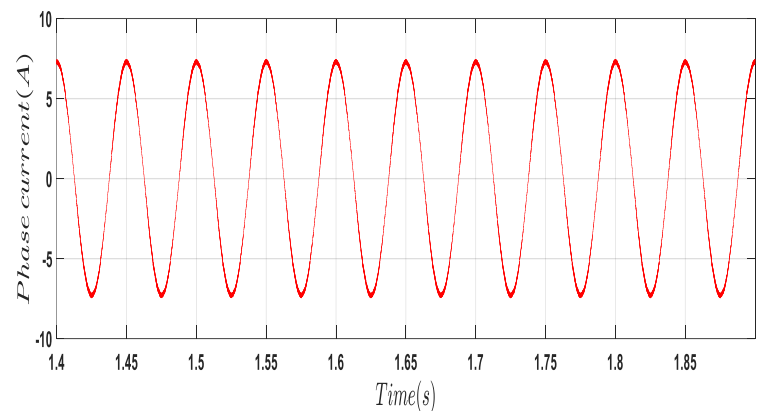

(b)

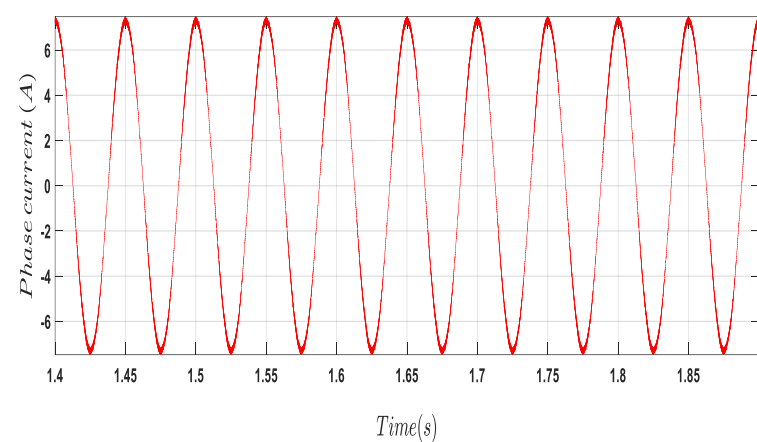

(c)

Figure 10 Stator Phase Current according to positioning zero voltage vector

(a) Approach (1). (b) Approach (2). (c) Approach (3)

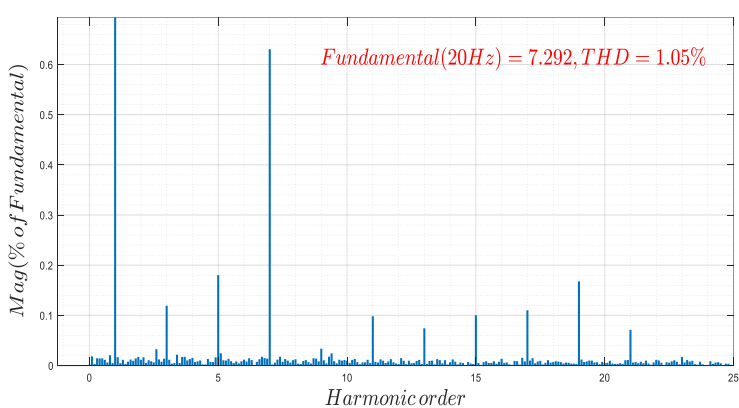

(a)

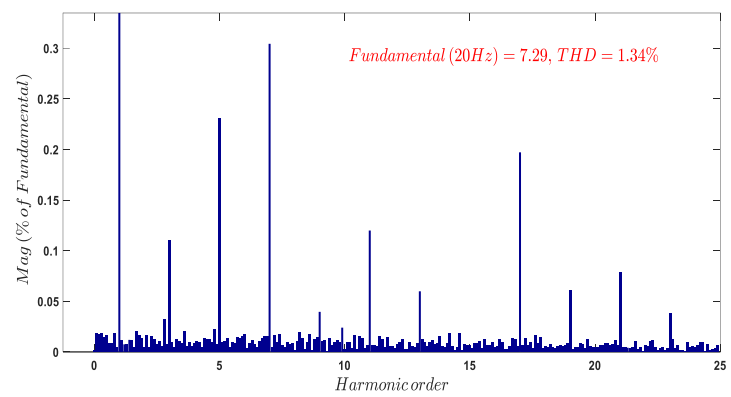

(b)

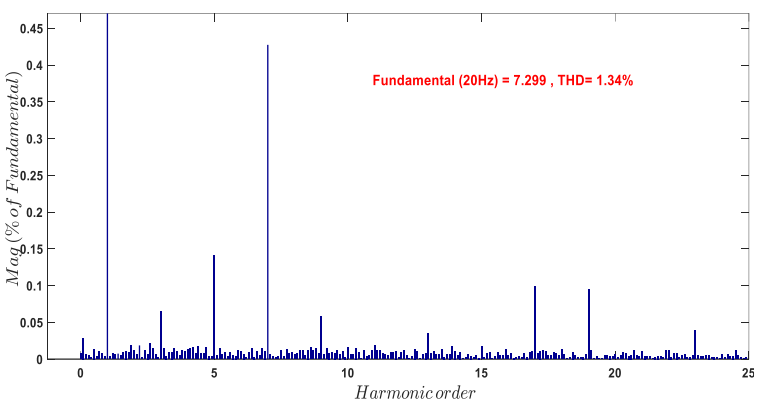

(c)

Figure 11 Stator Current Harmonic Analysis according to positioning zero voltage vector (a) Approach (1). (b) Approach (2). (c) Approach (3)

To be noted that for the three approaches envisaged; THD current and switching number, the following table:

Table 4. Swiching sequences evaluation

\begin{tabular}{cccc}
\hline $\begin{array}{c}\text { Appropriate positioning of the zero } \\
\text { voltage vector }\end{array}$ & Swiching Number & THD current & Fundamental (20 HZ) \\
\hline Approach (1) & 6 & 1,05 & 7,292 \\
Approach (2) & 5 or 4 & 1,34 & 7,290 \\
Approach (3) & 4 or 5 & 1,34 & 7,299 \\
\hline
\end{tabular}

Figure 12 shows that the stator currents in the subspace $\left(z_{1}-z_{2}\right)$ are too weak (amplitude 0.2 A) compared with the stator currents fundamental (amplitude 8 A). In Figure 13, the harmonic currents do not 
affect the torque output performance. Figure 14 shows that the machine speed achieves its reference with satisfying static and dynamic performance.

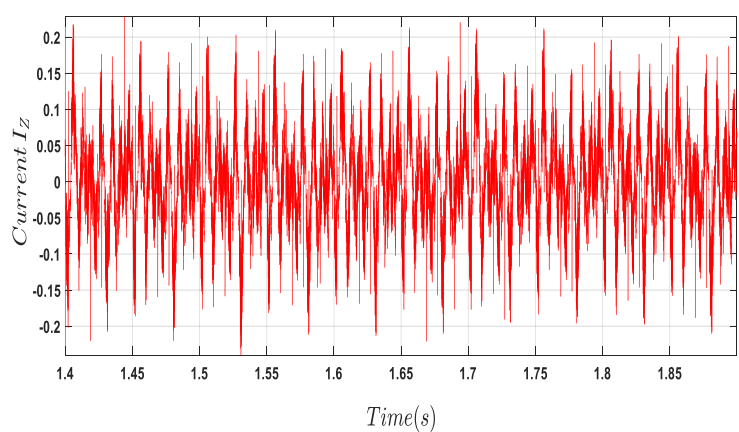

(a)

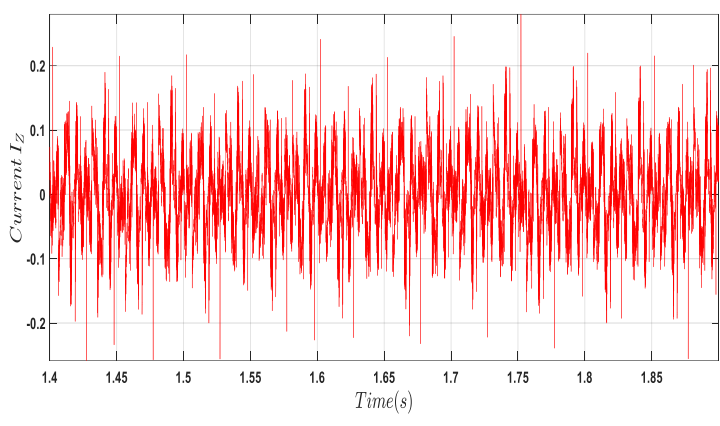

(b)

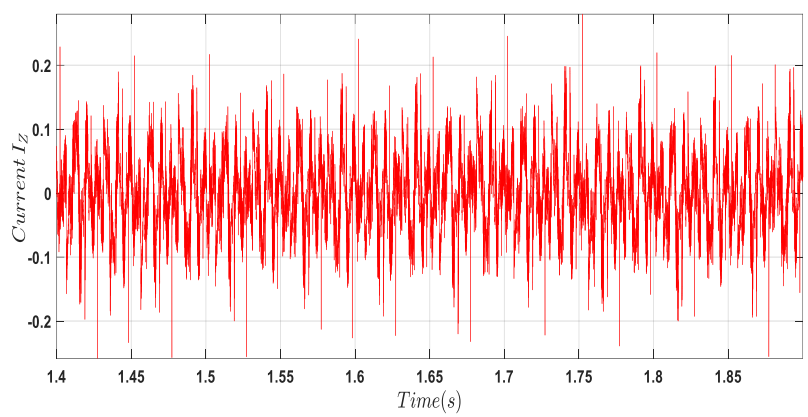

(c)

Figure 12. Stator Phase Current in subspace $\left(\mathrm{z}_{1}, \mathrm{z}_{2}\right)$ according to positioning zero voltage vector (a) Approach (1). (b) Approach (2). (c) Approach (3)

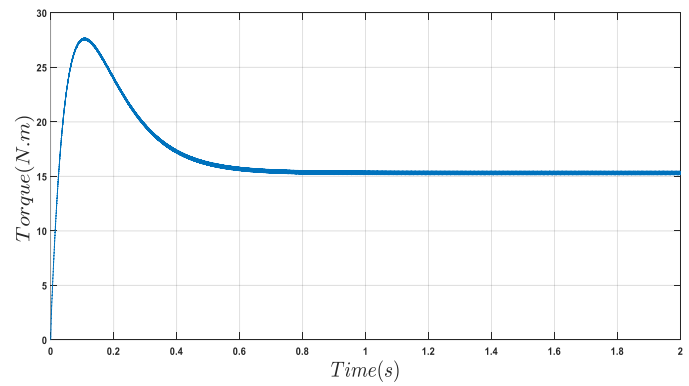

Figure 13. Machine's Torque

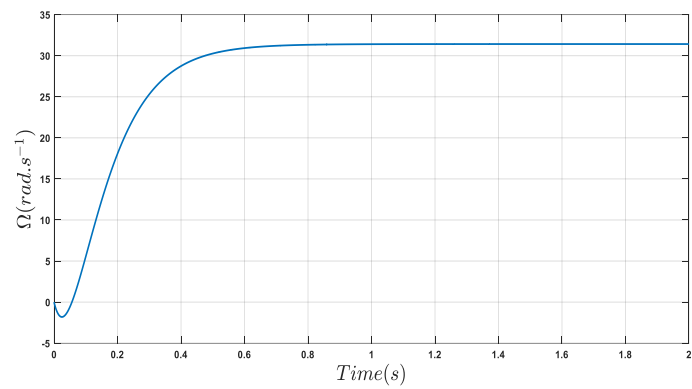

Figure 14. Machine's Speed

\section{CONCLUSION}

In this paper, a FOC strategy based on the 24-Sector Vector Space Decomposition (24SVSD) appropriate to the control machine drive system applied on electric ship prototype has been presented in order to reduce the current harmonics. The chosen four voltage vectors divide the $(\alpha-\beta)$ subplane into 24 sectors which is related to electromechanical energy conversion and each sector is $\pi / 12$ rad. This modulation approach is required to efficiently eliminates the stator current harmonics in $\left(\mathrm{Z}_{1}-\mathrm{Z}_{2}\right)$ and $\left(\mathrm{O}_{1}, \mathrm{O}_{2}\right)$ subspaces. The simulation results show that the proposed technique allows the notable reduction current harmonics. Thus, it is confirmed that the suggested strategy offers lower harmonic current analysis. This explains by an effective reduction to $1.05 \%$. Also, it is worth noting that a significant reduction in the stator current harmonics is associated with a $25 \%$ decrease in the switching losses corresponding to approaches (2) and (3), is observed at the level of the converter-machine combination. The results attest the effectiveness of the suitable modulation. Performing experimentation by an implementation on Digital Signal Processor (DSP) board of the proposed strategy will be the subject of the further works. 


\section{REFERENCES}

[1] Y. Zhao and T. A. Lipo, "Space Vector PWM Control of Dual Three-Phase Induction Machine Using Vector Space Decomposition", IEEE Trans. Ind. Applicat., Vol.31, No.5, pp.1100-1109, 1995.

[2] M.Hasoun, A.El Afia, K.Chikh, M.Khafallah and K.Benkirane, "A PWM Strategy for Dual Three-Phase PMSM Using 12-Sector Vector Space Decomposition for Electric Ship Propulsion," 2018 19th IEEE Mediterranean Electrotechnical Conference (MELECON), Mai 2-7, IEEE, pp.243-248, 2018.

[3] E.Levi, "Multiphase electric machines for variable-speed applications," IEEE Trans. Ind. Electron., Vol.55, pp.1893-1909, 2008

[4] Yi Guo and Xuekui Yan, "Research on matrix converter control multi-phase PMSM for all electric ship", 2011 International Conference on Electrical and Control Engineering, pp.3120-3123, 2011.

[5] M.B.R. Corra, C. B. Jacobina, C.R. da Silva, A.N. Lima and E.R.C. da Silva, "Six-phase AC drive system with reduced common-mode voltage", IEEE International Electric Machines and Drives Conference, pp.1852-1858, 2003.

[6] Drazen Dujic, Atif Iqbal and Emil Levi, "A Space Vector PWM Technique for Symetrical Six-Phase Voltage Source Inverters", EPE Journal, Vol.17, No.1, pp.24-32, 2007.

[7] Bulai Wang, Gu Wei, Jianxin Chu and Guo Yi, "A Novel Modeling for A Dual Three-phase Permanet Magnet Synchronous Machine," $200810^{\text {th }}$. Conf. on Control, Automation, Robotics and Vision, Hanoi, Vietnam, pp. 1720 December 2008, 2008.

[8] Yanjun Yu, Lixiao Gao, Yang Liu and Feng Chai, "24-Sector Space Vector Decomposition for a Dual ThreePhase PMSM," $201417^{\text {th }}$ International Conference on Electrical Machines and Systems (ICEMS), oct 22-25, Hangshou, China, pp. 1601-1606, 2014.

[9] H. Yan, Y. Xu, J. Zou and F. Zeng, "Phase current Reconstruction for Dual Three-Phase PMSM Drive in Electric Vehicles Using Two DC Link Current Sensors," 2016 IEEE Vehicle Power and Propulsion Conference (VPPC), pp. 1- 6, 2016.

[10] K. Yu, H. Guo, Z. Sun and Z. Wu, "Efficiency Optimization Control of Permanent Magnet Synchronous Motor for Electric Propulsion System", International Conference on Electrical Machines and Systems, pp.56-61, 2013.

[11] L Wang, D Zhang, Z. Wang, J.Chen, M.Cheng and N.Ren "Vector Space Decomposition Based Control of Neutral-Point-Clamping (NPC) Three-level Inverters Fed Dual Three-Phase PMSM Drives," IECON 2016- 42" Annual Conference of the IEEE Industrial Electronics Society, Oct 16, IEEE, pp. 2988-2993, 2016.

[12] Z. Wang, Y. Wang, J. Chen and Y. Hu, "Decoupled Space Decomposition Vector Based Space Vector Modulation for Dual Three-Phase Three-Level Motor Drives," IEEE Trans. Ind. Applicat., Vol.33, No.12, pp. 10683-10697, 2018

[13] L. Yuan, M.-L. Chen, J.-Q. Shen, and F. Xiao, "Current Harmonics Elimination Control Method for Six-Phase PM Synchronous Motor Drives," ISA Transactions, vol. 59, pp. 443 - 449, 2015.

[14] Valentin Oleschuk et al "Combined PWM Control of Multi-Inverter Installation with Two DC-Links", 2015 International Conference of Electrical Drives and Power Electronics (EDPE), pp. 94 - 98, 2015.

[15] H. Zhang et al, "Study on Series Control Method for Dual Three-Phase PMSM based on Space Vector Pulse Width Modulation", International Journal of Control and Automation Vol. 8, No. 1, pp. 197-210, 2015.

[16] W. Tiejun, S. Chenglin, C. Yongbing and J. Xiaoyi, "Researchon harmonics of multiphase induction motors", Proc. IEEE IEMDC, Antalya, Turkey, Vol. 2, May 3-5, pp.1524-1528, 2007.

[17] K.K.Mohapatra, R.S.Kanchan, M.R.Baiju, P.N.Tekwani and K.Gopakumar, "Independent field-oriented control of two split-phase induction motors from a single six-phase inverter," IEEE Trans. Ind. Electron., Vol. 52, No. 5, pp.1372-1382, Oct. 2005.

[18] R. Bojoi, M. Lazzari, F. Profumo, Senior Member, IEEE, and A. Tenconi, "Digital Field-Oriened Control for Dual Three-Phase Induction Motor Drives", IEEE Transactions on Industry Applications, Vol. 39, No.3, pp. 752760, 2003.

[19] Ping Zhang, Wei Zhang and Xiaofeng Shen, "Comparative Study of Field-Oriented Control in Different Coordinate Systems for DTP- PMSM," 2013 International Conference on Electrical Machines and Systems (ICEMS), Oct.26-29, pp.1015-1019, 2013.

[20] J. Pradeep and R. Devanathan, "Adoption of Park's Transformation for Inverter Fed Drive", International Journal of Power Electronics and Drive System (IJPEDS), Vol. 5, No. 3, pp. 366 - 373, 2015.

[21] M. Porselvi, R. Bojoi, M. Lazzari, F. Profumo and A. Tenconi, "Digital Field-Oriented Control for Dual ThreePhase Induction Motor Drives", IEEE Trans. Ind. Applicat., Vol.39, No.3, pp.752-760, 2003.

[22] X. Zhang, X. Xie and R. Yao, "Field Oriented Control for Permanent Magnet Synchronous Motor Based on DSP Experimental Platform", $27^{\text {th }}$ Chinese Control and Decision Conference (CCDC), pp.1870-1875, 2015.

[23] K. Yu, H. Guo, Z. Sun and Z. Wu, "Efficiency Optimization Control of Permanent Magnet Synchronous Motor for Electric Propulsion System", International Conference on Electrical Machines and Systems, pp.56-61, 2013.

[24] Khoudir Marouani, Lotfi Baghli, Djafar Hadiouche, Abdelaziz Kheloui, and Abderrezak Rezzoug, "A New PWM Strategy Based on a 24-Sector Vector Space Decomposition for a Six-Phase VSI-Fed Dual Stator Induction Motor", IEEE Trans. Ind. Applicat., Vol. 55, No. 5, pp.1910-1920, 2008.

[25] J. Karttunen, S. Kallio, P. Peltoniemi, P. Silventoinen and O. Pyrhonen, "Dual three-phase permanent magnet synchronous machine supplied by two independent voltage source inverters," Proc. Int.Symp. Power Electron.Electr. Drives, Autom.and Motion, pp.741-747, 2012. 


\section{BIOGRAPHIES OF AUTHORS}
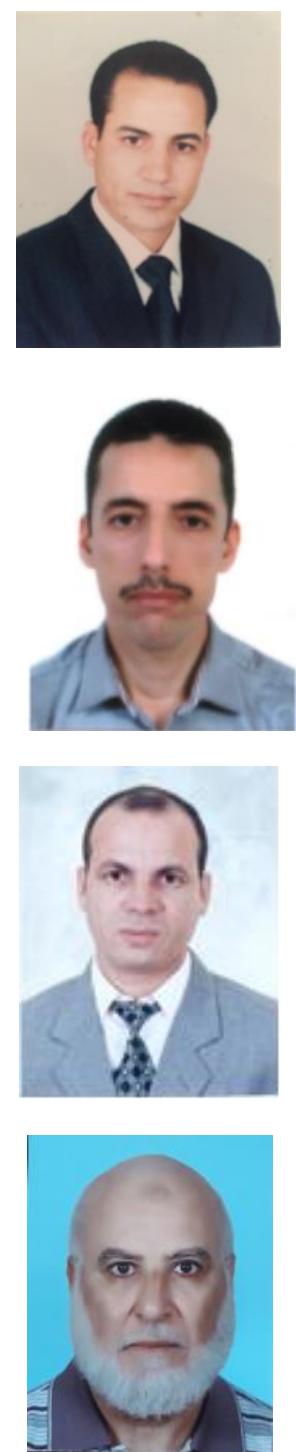

Mhammed Hasoun: was born in Khouribga, Morocco, in 1969. He received the Engineering degree in 1995 from Navy Royal School, Military Navy, Casablanca, Morocco; and the certificate of Navy Safety in 1996 at Cherbourg, France. From 1996 to 2008, he occupied the function of propulsion engineering chief in military ships various. In 2008 he joined the Navy Royal School, where he is currently professor at the Engineering Department. His current research interests are in the application of power electronics converters and motor drives for electric propulsion systems.

(E-mail: mhammedhasoun@gmail.com).

Aziz El Afia: He received B.Sc., M. Sc. degrees from Hassan II University, Casablanca in 1990, 1994 respectively and the Ph.D. degree in Electrical Engineering from The National High School of Electrical and Mechanical Engineering (ENSEM), Hassan II University, Casablanca in 2009. Since 2011 he has been working as a Professor of Power Electronic at the National High School of Arts and Crafts of Casablanca (ENSAM). His current research interests are in power electronics converters and control of machines and drives for application from automotive to renewable energy.

(Email: aziz.elafia@univh2c.ma).

Mohamed Khafallah: was born in Morocco in 1964. He received B.Sc., M.Sc. and Doctorate degrees from Hassan II University, Casablanca, in 1989, 1991 and 1995 respectively, all in Electrical Engineering. In 1995 he joined the National High School of Electricity and Mechanics (ENSEM), Hassan II University, Casablanca, Morocco, where he is currently professor tutor in the Department Electrical Engineering and chief of Laboratory Energy and Electrical Systems (LESE). His main research interests the application of power electronics converts and motor drives. He has published a lot of research papers in international journals, conference proceedings as well as chapters of books.

(Email: m.khafallah@gmail.com).

Karim Benkirane: was born in Morocco in 1960. He received B.Sc., M.Sc. and Doctorate degrees from Mohamed V University Rabat and University of Sciences and Technics at Languedoc (USTL), France, in 1978, 1983 and 1986 respectively, all in Electronics Engineering. In 1987 he joined the Royal Navy School (ERN), Casablanca, Morocco, where he is currently professor tutor in the Department Research. His main research interests the application of power electronics converts and motor drives. He has published a lot of research papers in international journals.

(Email: karbenkirane@yahoo.fr). 